\title{
An Opinion of Indian Manufacturing and Service Sector for Adopting Industry 4.0: A Survey
}

\author{
Pratish Rawat $^{1}$, Dr. Yashpal ${ }^{2}$, Dr. Jayant Kishor Purohit ${ }^{3}$ \\ ${ }^{1}$ Research Scholar, Poornima University, Jaipur, India \\ ${ }^{2,3}$ Associate Professor, Poornima University, Jaipur, India \\ E-mail: 1pratishrawat@gmail.com, 2yashpal.kaushik@poornima.org, 3jkp.research01@gmail.com
}

Article History: Received: 10 November 2020; Revised 12 January 2021 Accepted: 27 January 2021; Published online: 5 April 2021

\begin{abstract}
Industry 4.0(I4.0) a German project can influence whole industrial and business system by digital transformation of product design, smart manufacturing and delivered to consumer. Industry 4.0(I4.0) project combines the physical world and digital world together through cyber physical systems and helps SMEs in enhancing production processes and increase productivity through emerging technologies such as Internet of Things and Services, Machine learning, Virtual Reality, cloud computing, business analytics etc. However, adoption and implementation of Industry 4.0 project is not an easy task due to existence of various challenges. In the present study, a survey is conducted with 40 Indian manufacturing and service organisations to get their opinion on Industry 4.0 and the level of adoption of in their organization. The objective of this research is to identify the general awareness and understanding of the concepts of Industry 4.0(I4.0) and its related emerging technologies along with their implementation levels in selected organizations. With the feedback received from the selected organizations, this paper analyzes the results and give some discussion.
\end{abstract}

Keywords: Industry 4.0, readiness, barriers, SMEs, service sector, emerging technologies

\section{Introduction}

Industry 4.0 (I4.0) brings a new point of view to the manufacturing and service sector which integrated with the new and emerging technologies to get efficient and effective outcome with optimum utilization of resources in manufacturing and service organisations. Industry4.0 is the integration of cyberphysical-systems with information technology. The new technologies like IoT enabled smart machines, cloud technology, and data driven manufacturing facilities, triggering actions and independently controlling each other creates cyber-physical-systems.

Industry 4.0 makes organisations smarter and more flexible by furnishing service, manufacturing and production facilities with sensors, actuators and autonomous-systems. In this way, equipment and machines can achieve a higher level of self-optimization and automation. This is called smart factory where cyber physical systems monitor and controls the physical processes by using autonomous devices which are communicating with each other and able to Decentralized decision-making based on selforganizing mechanism [1].

In 2011, during Hannover trade fair in Germany the term Industry 4.0 was introduced and later it was embraced by German government in policy making to take extra edge in competitive advantage in German Industrial sector. After that the concept of Industry 4.0 has spread to other countries in the world such as India, Australia, Japan, China etc. and evolved as the fourth industrial revolution.

This digital transformation enables us to collect large amount of data that can be analyzed across machines and provides more dynamic, flexible, and highly efficient processes which helps to provide high quality mass customized products and services at reasonable costs. This next generation revolution will increase productivity, improve GDP, promote growth in industrial and service, and modify the skill requirements in human resources i.e. it is ultimately going to change the competitiveness of industrial and service sectors as well as the regions [2].

The basic concepts behind the Industry 4.0 are integration of value chain including interrelationships among suppliers, manufacturers and consumers as well as human and machine interface 
through adopting emerging technologies like Internet of Services, Internet of Things, Big-Data, Robots, Simulation Technologies, System Integration, Cloud-Technology, Cyber Security, 3-D Printing, Rapid Prototyping, Cyber-Physical-Systems and Augmented Reality.

Industries in Scandinavian countries adopted the Industry4.0 very quickly with respected to many of other countries in the world by following the path and model of Germany [3]. manufacturing sector have a major contribution to their economies and this is the major driving force. Other developed nations such as Japan, Germany, China, Australia are greatly inspired by the leaders in Industry 4.0 and investing huge amount in developing their strategies and business models to adopt and implement Industry 4.0. However, in current scenario and economic slowdown after COVID-19 not every nation is really ready for adoption and implementation of I4.0. In India, Industry 4.0 recently emerged and Manufacturing organizations specifically MSMEs facing the various challenges in adopting the Industry 4.0 technologies.

The micro, small, and medium enterprises (MSMEs) sector is a very important industrial sector and playing a crucial role in the Social and economic development of India. MSMEs account for about 29\% of India's GDP and has over 65 million such MSMEs units functioning throughout the geographical expanse of the country. They generate employment opportunities to more than 120 million persons and hence function as the second largest employment creating sector after agriculture in India. The Ministry of Micro, Small \& Medium Enterprises has set up a target to increase the contribution to GDP to 50\% by 2025 as India becomes a \$5 trillion economy [4]. However, micro, small and medium-sized enterprises are also facing many challenges, such as outdated technology, low supply chain efficiency, and increased global competition. Digital transformation may be a suitable solution for success in the age of Industry 4.0.

Industry 4.0 is also that manufacturers must use technology to digitize in order to maintain their future business status. I4.0 influence the whole service and industrial systems by digital transformation of product design, smart manufacturing and delivered to consumer. Industry 4.0 project combines the physical world and digital world together through cyber physical systems and helps MSMEs in enhancing production processes and increase productivity through emerging technology such as Internet-of-Things (IoT), artificial intelligence (AI), cloud technology, business analytics etc. However, adoption and implementation of I4.0 project is not an easy task due to existence of various barriers. The micro, small, and medium enterprises (MSMEs) sector must completely understand the various opportunities and challenges which are associated with these emerging technologies and establish strategies to adopt these technologies to survive and compete in this new digital era of I4.0[5].

The present research identifies the key opportunities and barriers to implementation Industry4.0 project in manufacturing and service sector of India and degree of readiness through a survey study. The study also discussed the various challenges and problems that need to be solved to establish a business model in the MSME made in India using Industry4.0 technology. The results of this article put forward some recommendations that can provide a clear understanding of business reality and show the path of Indian MSMEs towards intelligent manufacturing with reference to Industry4.0.

\section{Research methodology}

This research collected the views of experts working in the organizations of Indian manufacturing and service sectors on the challenges regarding the adoption of Industry4.0 and emerging technologies related to it. An approach of random sampling [6], was adopted in this study. The researchers first developed a semi-structured typed questionnaire and circulated it for data collection. The questionnaire consists of various topics, such as the awareness level about the concept of industry4.0, ICT tools and infrastructures, drivers for the business, major barriers in adoption of Industry4.0 and future-plans related to its implementation. After rounds of discussion and improvements, the questionnaire was finally framed. The questionnaire was distributed to fifty industrial experts who are working as manager or engineer in technical domain of different organizations and industries. This study is based on the data collected from the fourty three responses since the response rate is $86 \%$.

\section{Result analysis}

\subsection{Results and analysis}

This section briefly discusses and presents the questions and analysis results of the questionnaire. 


\subsubsection{Awareness about Industry 4.0 concept}

The implementation of the next generation transformation of Industry4.0 requires an in-depth knowledge and understanding of manufacturing digitization. In order to determine the level of awareness of the interviewees about Industry4.0, ask them to say the first thing they think of when they hear "Industry4.0". In order to solve the lack of clarity in the response and justify the written response, the author used a five-point Likert scale. Therefore, the level of participation of respondents was represented as "very poor", "poor", "average", "good" and "very poor".

$08 \%$ of respondents have a high level of understanding of the core concepts of I4.0 and its core technologies as shown in figure 1 . The results also shows that $18 \%$ of manufacturers and service providers have a good awareness about the concept of I $4.0 .30 \%$ of them have a moderate understanding of the concept of IIoT. The results show that $32 \%$ of the respondents have average awareness about Industry 4.0 , and the remaining respondents $(12 \%)$ have very little or no awareness about the fourth industrial revolution. For the sustainable transition process to a functional I4.0 environment, organization should emphasize on the importance of appropriate skills, education, working conditions, and information levels. We believe that appropriate education and the dissemination of relevant information are essential to the process of achieving a sustainable transition from the current conditions in India to Industry 4.0 and its characteristics.

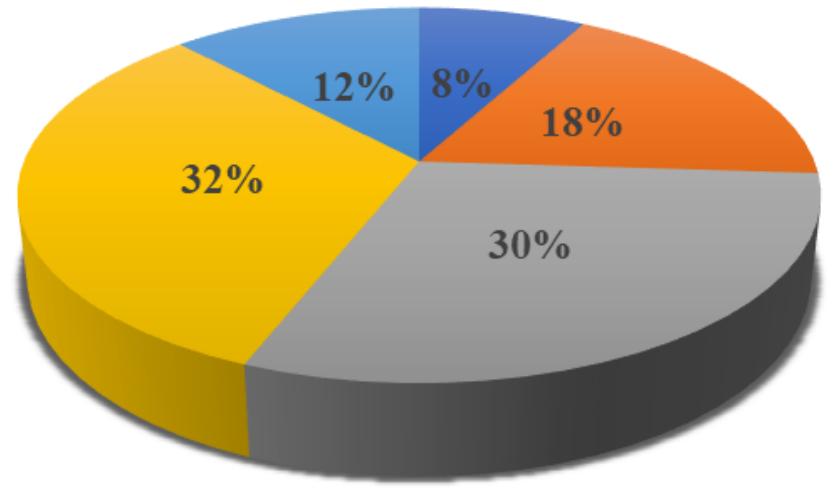

\section{घ Very Good $\quad$ Good $\backsim$ Average $\backsim$ Poor $\quad$ Very Poor}

Figure 1: Awareness about Industry 4.0 concept

\subsubsection{Relevant to organization}

I4.0 has distinguished characteristics that can considerably affect the manufacturing organizations and service providers in various ways. The digital transformation of business models and value-chains can be done by combining integrated systems and intelligent production processes and services. Therefore, participants must identify the company sectors that can get advantages from all aspects of I4.0.

Figure 2 shows that about $26 \%$ of respondents feels that Industry 4.0 can greatly change their production, manufacturing and service systems. $30 \%$ of manufacturers said that the I4.0 revolution can impact in all aspects of their business, while $19 \%$ of respondents trust that IT is the only sector that can be benefited from I4.0. According to the survey outcome, it was also found that $06 \%$ of the respondents believed that Industry 4.0 has no aspects that could enhanced their business. Similarly, customer support services $(5 \%)$, product innovation and development(10\%), inventory and procurement management( $2 \%)$, and customer relationship management $(2 \%)$ are the last four in this ranking.

Tata motors have invested in improving the skills of our employees at home, and have researched and developed implementation solutions that can increase production efficiency. Motherson Group have used additive manufacturing as a tool to improve overall efficiency, and they firmly believe that by using Industry 4.0 tools, they need to scale up and cannot be used as a tool to reduce manpower. Bharti Airtel and Nokia have cooperated to provide enterprises with private industry 4.0 solutions based on LTE. I4.0 relies on low-dormancy, good-reliability networks, robotics and AI functions to promote a new level of automation and data sharing in the manufacturing industry, thereby improving operational 
efficiency and reducing costs. Smart Controls India Ltd proposed to customers a solution method based on Industrie 4.0, which involves identifying, acquiring all possible data and passing it from the production line to a data analysis engine, which can analyze the data, learn from it, and predict the quality during production. Bajaj Auto have made a huge investment in a specific area of I4.0 implementation in their industries.

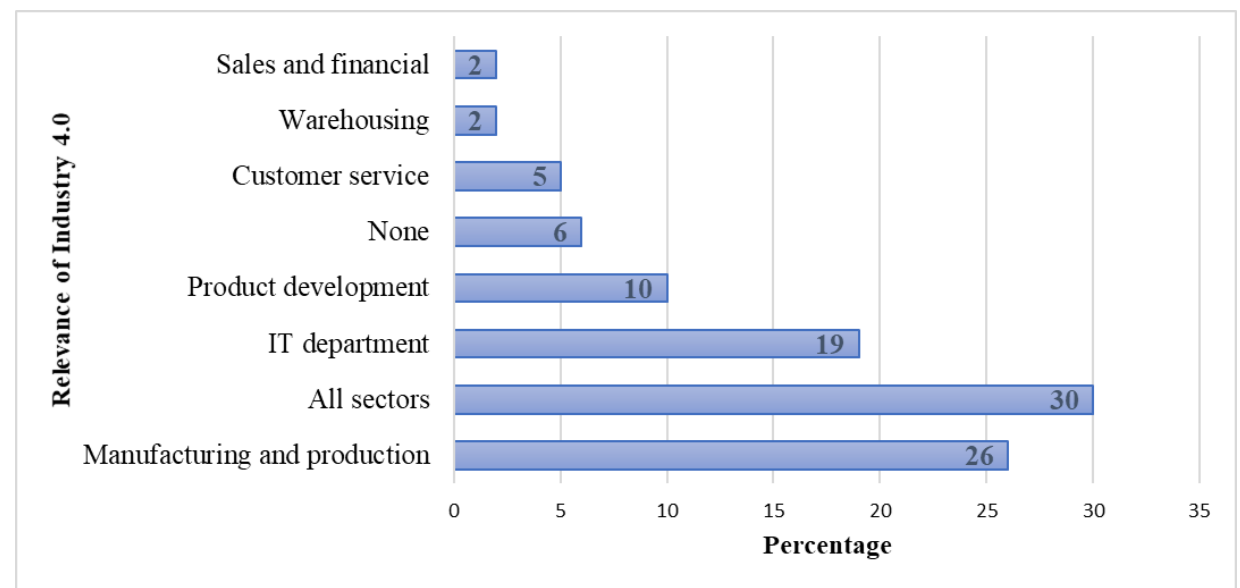

Figure 2: Relevance of Industry 4.0 to organization (in percentage)

\subsubsection{Application of Information technology in Organizations}

The integration of ICT tools in production and automation is one of the applications of Industry4.0. Digitization, networking and data analysis are the core concepts in advanced information technology. The effective strategies focus on the functions needed to develop new business models to adopt digitization. Therefore, the current situation of the manufacturer must be tested based on the implementation of the computer system. Participants were asked about the department that uses the information technology management process (there may be several options). In the survey it was observed that the $88 \%$ respondents used information technology infrastructure extensively in financial \& accounting systems, and also realized considerable gains in purchasing and inventory management $(80 \%)$. The use of information technology allows companies to improve traditionally implemented logistics processes to provide production factors, production factors and production factors required for production, as well as the logistics of information services provided by technology companies online. Information technology has had a major impact on accounting. It enables organizations to use IT systems to store, record and analyze the financial transactions. IT networks and processing systems reduces the time taken by the accountants to prepare financial data and present it to management. The IT system allow enterprises to create and quickly analyze the individual reports for management for decision making. The IT enabled accounting system include: higher functions, higher accuracy, faster processing speed and better external reports. In addition to that it was found that production planning and scheduling with $78 \%$ responses, sales and customer relationship management with $70 \%$ responses, quality control with $57 \%$ responses and production machinery control $35 \%$ responses are ranked lower in the ranking with lower profits positions. According to the information provided by the interviewees, the last two industries with the lowest IT contribution are after-sales service $(27 \%)$ and energy management (19\%). 36\% of manufacturers and service providers use information technology for other purposes. 


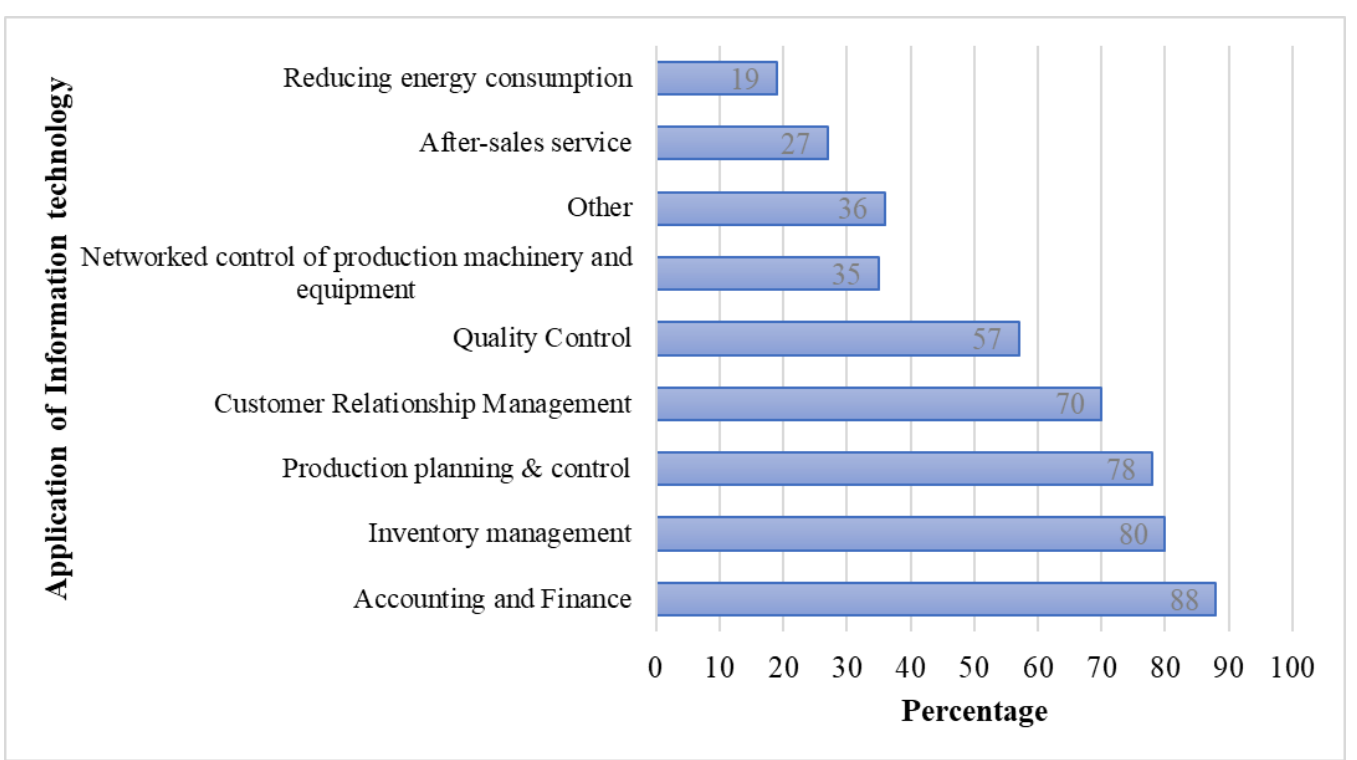

Figure 3: Application of Information technology in Organizations (in percentage)

\subsubsection{Benefits to Organization}

Unless manufacturers and service providers accept it, the I4.0 concept will not be implemented successfully, and unless and until all the advantages and challenges are being clear, they will not adopt the technologies linked with I4.0. In order to determine the expectations of Indian manufacturers and service providers for their businesses on the advantage from Industry-4.0, we analyzed them. Figure 4, represents that $39 \%$ of manufacturers and service providers expect the successful and effective implementation of Industry 4.0 will reduce manufacturing or service costs, while $27 \%$ of participants believe that increase in operational flexibility is one of the most important result of I4.0 for their business whereas $6 \%$ of the respondents trust that with Industry 4.0, they can develop a new innovative business models, and $6 \%$ of the respondents also believe that with correct implementation of Industry 4.0 in their organizations, open up the paths for further product innovation. However, $4 \%$ of manufacturers and service providers believed that I4.0 technologies will not have any reasonable impact on their business, nor can they provide better services.

Industry 4.0 technology enables companies to create smart factories that are more efficient, more efficient, more flexible and more responsive to customers. Industry 4.0 technology makes it possible to eliminate the need to lay off workers and implement significant cost reduction measures. Real-time quality control and monitoring helps reduce waste. Predictive maintenance avoids expensive repairs and downtime. Automation can save labor costs, increase output and ensure quality. The combination of all these can reduce operating costs.

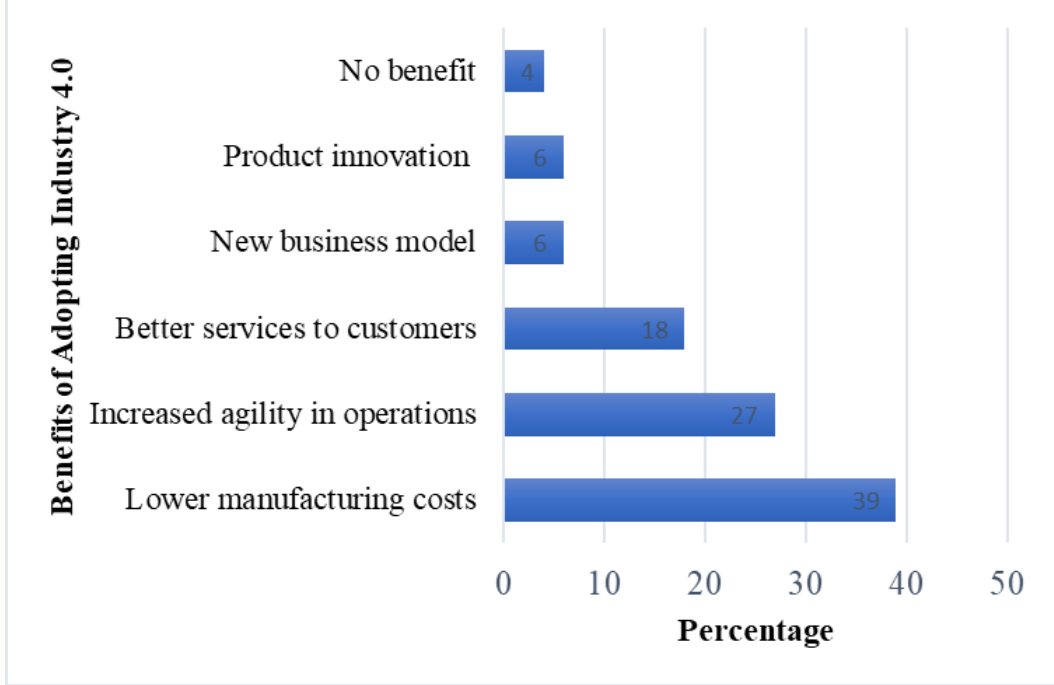

Figure 4: Benefits of industry4.0 to Organization (in percentage) 


\subsubsection{Aspiration for adopting industry 4.0}

Industry 4.0 technologies definitely improve the organization's productivity and efficiency of processes and services. In order to move towards Industry 4.0, it is essential to realize and implement digital functions throughout the enterprise. This is a time taking process, so to obtain or maintain an advantage of first move over competitors, decision makers will need the commitment and a financial support for implementation of technologies related to I4.0 from the top management. For them, it is vital to assess their maturity readiness to I4.0 and take the achievable goals for the coming 5-years. Respondents were asked whether their organization's business plans for times to come for Industry-4.0 implementation have proven their worth. It was found that $30 \%$ of manufacturers and service providers are intend to adopt I4.0 in the next 12-months, whereas $25 \%$ of respondents said they need 13 to 24 months to prepare the required infrastructure. However, $10 \%$ of the manufacturers and service providers have no future plans to adopt the technologies related to I4.0, while the remaining $35 \%$ respondents ready to digitize their organizations in the next 3-5 years.

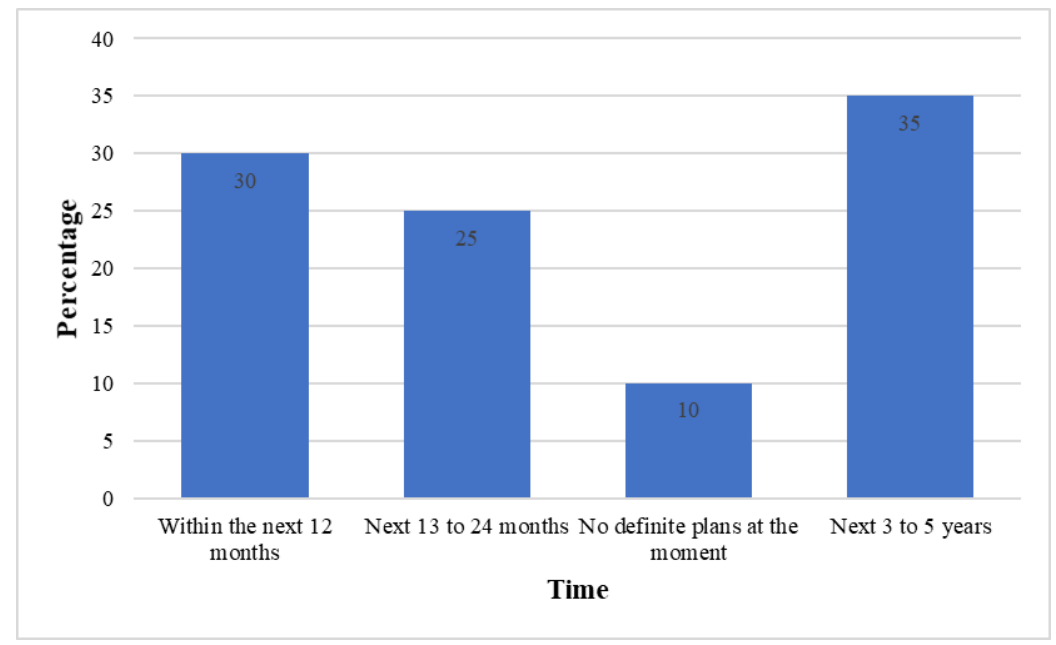

Figure 5: Aspiration of organizations for adopting industry 4.0

\subsubsection{Major challenges and barriers}

Industry 4.0 and its technologies has many benefits but still manufacturers and service providers are facing serious challenges that must be considered and resolved for effective adoption of I4.0 [7]. From a lack of organizational culture and training, a shortage of talents to the implementation of innovative business and revenue models that take advantage of digital transformation opportunities and conduct research, the best and feasible solution must be determined [8]. Figure 6 represents the respondents' thoughts on future barriers and challenges with multiple choices. $79 \%$ of service providers and manufacturers think that the most critical obstruction to implementing Industry 4.0 in their companies is obtaining seed funding. 54\% of participants said that they are engaged in handling other important challenges in the organization and have no plans for I4.0. In addition, the shortage of personnel trained in Industry-4.0 is another problem, preventing $48 \%$ of manufacturers and service providers from adopting I4.0, and $25 \%$ of them feels that they cannot use the appropriate equipment and software required by India. $15 \%$ of participants mentioned other obstacles to I4.0, such as challenge in convincing decision-makers about the feasibility and importance of the Industry-4.0, inadequate ability to integrate into the current scope of operations, and lack of awareness about I4.0. 


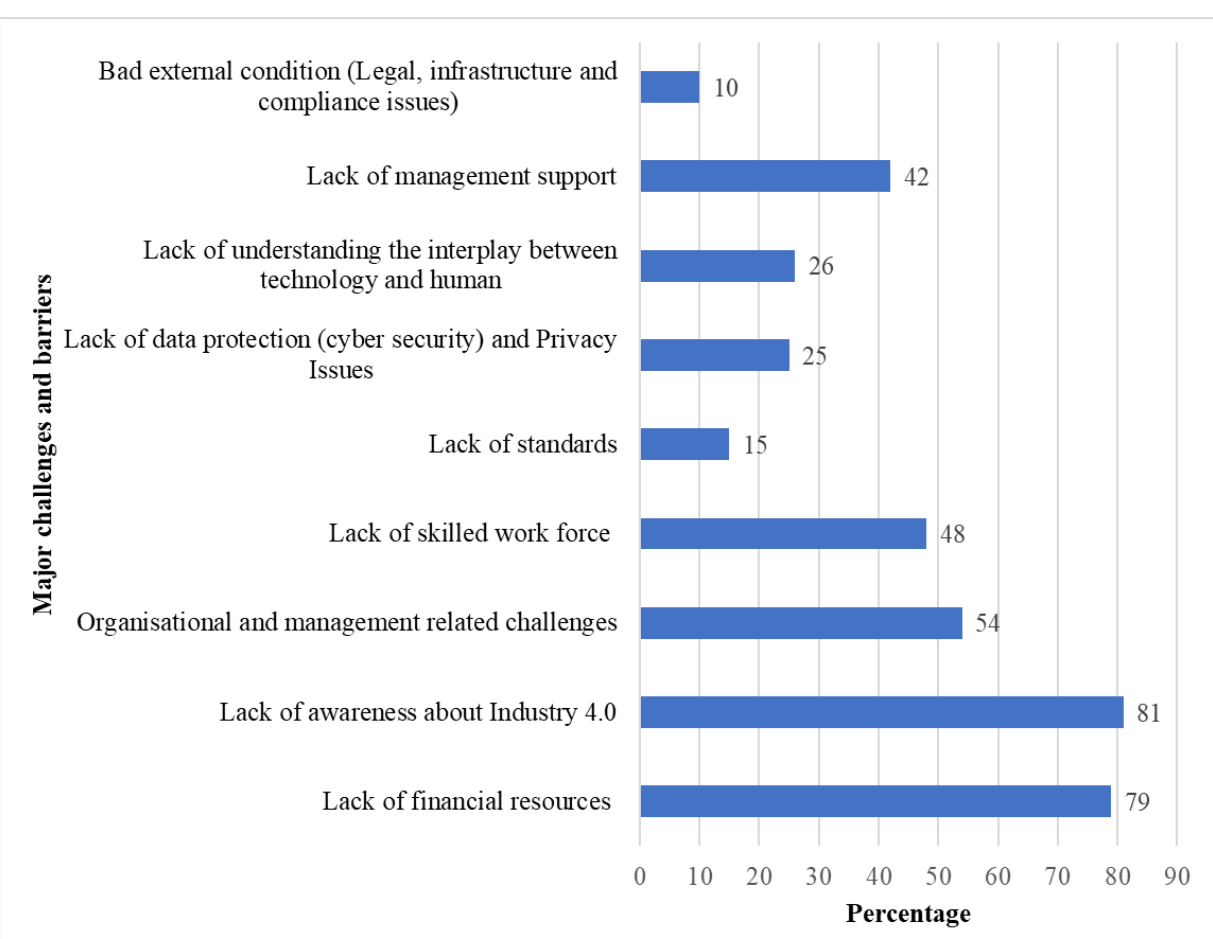

Figure 6: Major challenges and barriers to adopt industry 4.0 (in percentage)

\subsection{Discussions}

The outcome of this survey study showed that the Indian manufacturers and service providers have insufficient understanding of concept of Industry 4.0 and its basic technologies. More than seventy percent of the partaker in this survey showed a medium or low-level of awareness about the concepts of I4.0. It is vital for service providers and manufacturers to find ways to enter new and innovative areas of value creation rather than gradual improvements. They should also understand the changes brought by the technologies related with Industry4.0 and improve their skill of adopting to these changes in business and models of revenue to develop future chances and minimize risks. I4.0 can greatly change the way; the companies doing business and empower them to take advantage of new opportunities of value-creation. In order to achieve this digital transformation, manufacturing and service provider companies and their leaders must have a deep understanding of the concept of Industry 4.0 and its associated technologies and explore how to add value in their organizational environment. Participants in this survey pointed out that Industry 4.0 is most important to manufacturing processes and services. This result is fully in line with the main concept of Industry 4.0 and its ultimate aim, which is to create an intelligent production system. Industry 4.0 is expected to increase productivity, improve quality and increase flexibility, allowing Indian manufacturers to meet the challenge of mass-producing customized products in a short period of time.

IT infrastructure will play an important role in connecting the different stages and providing specific methods for managing them. In addition, the development of new industry paradigms based on IIoT requires IT infrastructure, and IT administrators and technicians support development in new ways. This proves that the participant's response is reasonable. These participants emphasized that the concept of Industry 4.0 is more relevant to other departments than its IT department. Manufacturers participating in the survey are mainly small and medium-sized enterprises that use old equipment and workstations to go offline. Information cannot be transferred freely within the company, but isolated on a separate area of automation. The supply chain management of these organizations is a sequence of various processes, from the evolution of product to its production till distribution to consumers. This is the reason why only a less interviewees consider Industry 4.0 concepts related to their operations like sales and service, development of product and inventory management. Few interviewees also pointed out that Industry 4.0 may have nothing to do with its business activities and production processes. It may be related to the insufficiency of an understanding of the concept of Industry4.0. In addition to this, the scattered and independent work and flow of information within the company prevented them from 
finding connections between advanced paradigms such as Industry4.0 and their related technologies and systems.

Most of the Indian manufacturing and service provider organizations surveyed said, that in various areas, they didn't have all the required IT-infrastructure to digitally transform their enterprise into a smart factory. Still, they localized digitized some of their departments. In current study, maximum participants use IT-infrastructure to transform their financial activities to be paperless. Converting traditional mainstream financial systems to server and network systems can have a significant impact on the way organizations implement smart business. The collaboration of these advance digital financial systems with other network systems that can change the functions of accounting and finance, from record-keeping to guiding strategies reporting for the whole organization. In addition, more than fifty percent of manufacturers and service providers use IT technologies like SAP, ERP, MIS and CRM to control various processes and services and also monitor and control the quality of service, operations and products [9]. These technologies can be considered as the support system of Industry4.0 in the established manufacturing and service sector, and only need to be modify and connected to the various other systems to build a smart business. Notably, due to the digitization and control of computer systems, after-sales service and energy management systems have received the least attention among Indian manufacturing companies.

Industry4.0 obtains customer feedback through the after-sales service provided, so that mass customization can be carried out. The lack of real-time systems and methods for collecting and analyzing customer feedback and needs prevents companies from seeing themselves as a smart and digital enterprise. SMEs companies continue to face lack of finance issues. They adopt the effective strategy to decrease their production costs, improve efficiency of labor and use emerging technologies [10]. Even though "Industry4.0" asked initial investment, once intelligence is built into processes, services and products, overall costs will drop. Reduction in production and operating costs is one of the most important motivation for survey participants to achieve Industry 4.0. They believe to obtain better quality with less time and less materials, thereby reducing operational and personnel costs. Short life cycle and high variability of the products require agility and flexibility in the manufacturing processes. This is the reason why manufacturers want to streamline the structure of their production system. These production systems can be quickly re-construct to meet dynamic requirements of product. Industry4.0 provides factories with outstanding agility without compromising with the service offered, cost, quality or speed. When a smart product has data about its characteristics, the entire production processes will speed up production. Industry4.0 has lower costs, better quality and stronger customer service capabilities, making manufacturers the preferred for the current and potential consumers [11].

It also enables the company to innovate quickly and provide high-quality, personalized products, paving the way for higher revenue. However, only a few respondents believe that I4.0 can bring companies higher income or greater production innovation. Respondents who believe that Industry 4.0 may not benefit their business should conduct a thorough investigation. This idea may be mainly due to a lack of adequate awareness of the opportunities of I4.0, or due to manufacturers' concerns about the risks inherent in the I4.0. Although Industry4.0 is expected to bring hope to the manufacturing industry, its implementation takes time and difficulties. Industry 4.0 contains many aspects and therefore seems to be a vision for the future, so companies can face various types of barriers based on economic, environmental, scientific, technological, social and political issues $[11,12,13]$. This vision leads to more complexity at the micro levels of the manufacturing and service processes. In particular, SMEs are unsure about their requirements of financial and technical resources for adopting the technologies related to Industry 4.0 and their results on their business models $[14,15,16]$. The initial requirements of funds to implement Industry 4.0 is the biggest challenge facing Indian manufacturers and service providers. Manufacturers worry about whether they need to invest in the implementation of Industry4.0 in order to bring benefits to their business. Unlike large companies that invest in their own technological capabilities, small and medium-sized companies be likely to collaborate with external technical support and hold-up the financial investment until the technology development cost is reduced. Another concern of the interviewees is the lack of time to delve into various areas of Industry 4.0 and develop business plans. Since many obstacles and barriers, internal and external, must be identified and resolved, the company focuses on the innovation of its current business model. For managers, developing innovative and commercially viable business models is also a challenge. 
Manufacturing companies need to ensure that their employees and employees understand and prepare for business changes related to digitalization. According to the survey results, one of the biggest concerns of manufacturers is the lack of well-trained personnel around them. The company is fully aware, that along with the investment in technology infrastructure, they also need to invest in developing leadership and employees training. It is well known that in a country like India, the lack of proper training systems will pose a challenge to their business. In addition, the lack of a local consulting team with professional experience in Industry 4.0 is another problem for manufacturers to shift their business to digitalization. Indian manufacturers and service providers are also concerned about the accessibility of suitable technology and software needed to achieve Industry 4.0. Most of these organizations uses older equipments, tools and software. In addition, your existing infrastructure is fragmented and decentralized, leading to poor network conditions. In order to realize the digitization of business, companies need to purchase different components, such as sensors, control systems, transducers, actuators, IT networks, sales and customer-oriented applications. Participants in this survey also highlighted other barriers to the Industry 4.0 implementation, such as challenges in persuading top management of the feasibility and concept value, and lack of ability to adapt to the footprint. Current operating conditions and lack of awareness of concepts Industry 4.0. Many of respondents in current study showed their interest to adopt "Industry 4.0" in upcoming 5 years because they believe that it is a feasible solution that can change their business. In addition to advantages, Industry 4.0 will also bring competition among organisations in manufacturing and service sectors. Therefore, to stay ahead of the competition, it is not only necessary to purchase specific tools and software, and observe how they complete the work. In order to meet with this competition, manufacturers strive to keep up with the development of new tools, equipment and technology. Not only must the company find the source of external changes, but it must also thoroughly study its business plans and strategies. Decision makers at the strategic and management levels must determine the strengths and technological gaps of their companies in the digital-era and set milestones for the next upcoming years.

\section{Conclusion}

This article represents the outcome of the study, conducted in the Indian manufacturing and service industry that will implement Industry 4.0 to upgrades and transform small and medium enterprises (SMEs) in the coming future. You can get analysis and brief ideas from this document. When considering the concepts and solutions of Industry 4.0, they are very important and useful for manufacturing companies. In an actual case study in India, future research will be conducted by developing implementation model and validate it. Specific procedures should be designed to verify the different stages, and the qualitative analysis and quantitative analysis should be provided to validate the model. In addition, implementation model must have more details such as, in each phase of the pilot project, you will continue to study, to define the scope of the test, to set targets and proposed feasible technical solutions, etc.

\section{References}

[1] European Parliament, Economic and Scientific Policy: Industry 4.0, 2016,

http://www.europarl.europa.eu/RegData/etudes/STUD/2016/570007/IPOL_STU(2016)570007_EN.pdf, access date: 10.10 .2020 .

[2] Boston Consulting Group, https://www.bcg.com/capabilities/operations/embracing-industry-4.0rediscovering-growth.aspx, access date: 10.10 .2020

[3] Group, I., Digitalisation and automation in the Nordic manufacturing sector - Status, potentials and barriers. 2015.

[4] Economic Times "MSME sector poised for mega transformation in 2020" https://economictimes.indiatimes.com/small-biz/sme-sector/msme-sector-poised-for-mega-transformationin-2020/articleshow/73028478.cms?from=mdr access date: 30 December 2020.

[5] Rawat P and Purohit JK "A review of Barriers in adoption of Industry 4.0 in Indian Micro, Small, and Medium Enterprises (MSMEs)" International Conference on New and Renewable Energy Resources for Sustainable Future (ICONRER 2019), Swami Keshvanand Institute of Technology, 2019.

[6] Borrego, M., E.P. Douglas, and C.T. Amelink, Quantitative, qualitative, and mixed research methods in engineering education. Journal of Engineering education, 2009. 98(1): p. 53-66. 
[7] Rawat P, Purohit JK and Kumar D, Industry 4.0 in Manufacturing Sector: A Review. Dogo Rangsang Research Journal, 2020. 10 (6); p. 180-191.

[8] Rawat P and Purohit JK, A Review of Challenges in Implementation of Industry 4.0 in Indian Manufacturing Industry", International Conference on Recent Trends and Innovation in Engineering, 2019.

[9] Davies, R., Industry 4.0. Digitalisation for productivity and growth. Briefing from EPRS. European Parliamentary Research Service, 2015.

[10] David, S., L. Roger, and N. David, The characteristics and strategies of high growth SMEs. International Journal of Entrepreneurial Behavior \& Research, 1995. 1(3): p. 44-62

[11] Khan, A. and K. Turowski. A Survey of Current Challenges in Manufacturing Industry and Preparation for Industry 4.0. in Proceedings of the First International Scientific Conference "Intelligent Information Technologies for Industry" (IITI'16). 2016. Springer.

[12] Zhou, K., T. Liu, and L. Zhou. Industry 4.0: Towards future industrial opportunities and challenges. in Fuzzy Systems and Knowledge Discovery (FSKD), 2015 12th International Conference on. 2015. IEEE.

[13] Chen, T. and H.R. Tsai, Ubiquitous manufacturing: Current practices, challenges, and opportunities. Robotics and Computer-Integrated Manufacturing, 2017. 45: p. 126-132.

[14] Schumacher, A., S. Erol, and W. Sihn, A Maturity Model for Assessing Industry 4.0 Readiness and Maturity of Manufacturing Enterprises. Procedia CIRP, 2016. 52: p. 161-166.

[15] Xu, X., Machine Tool 4.0 for the new era of manufacturing. The International Journal of Advanced Manufacturing Technology, 2017: p. 1-8.

[16] Zhong, R.Y., Q. Dai, T. Qu, G. Hu and G. Q. Huang, RFID-enabled real-time manufacturing execution system for mass-customization production. Robotics and Computer-Integrated Manufacturing, 2013. 29(2): p. 283-292. 